\title{
Analytical Approximate Solution for Nonlinear Behavior of Cantilever FGM MEMS Beam with Thermal and Size Dependency
}

\author{
Youhong Sun, ${ }^{1}$ Jinhua Cheng, ${ }^{1}$ Zhigang Wang, ${ }^{1}$ Yongping Yu $\mathbb{D},{ }^{1}$ \\ Lieyu Tian, ${ }^{2}$ and Jing'an $\mathrm{Lu}^{2}$ \\ ${ }^{1}$ College of Construction Engineering, Jilin University, Changchun 130021, China \\ ${ }^{2}$ Guangzhou Marine Geological Survey, Guangzhou 510075, China \\ Correspondence should be addressed to Yongping Yu; yuyongping@jlu.edu.cn
}

Received 20 December 2018; Revised 29 May 2019; Accepted 8 June 2019; Published 11 July 2019

Academic Editor: Gaetano Giunta

Copyright (c) 2019 Youhong Sun et al. This is an open access article distributed under the Creative Commons Attribution License, which permits unrestricted use, distribution, and reproduction in any medium, provided the original work is properly cited.

This paper is concerned with the nonlinear static behavior of a cantilever functionally graded material (FGM) microbeam with the influence of thermal stress and the intermolecular force. A significant extension of the recent works of constructing analytical approximate solutions to a clamped-clamped FGM MEMS/NEMS beam is formed in the paper. Based on the modified couple stress theory and an internal material length-scale parameter, the governing equations account for the microbeam size dependency. Note that the thermal force and moment in boundary condition make procedure of solution more complex. The combinations of Galerkin method and the assumption of deflection function are used to establish analytical approximate solutions which have brief expressions. Good agreements of approximate results are found for large range of free-end deflection of cantilever FGM microbeam through comparing them with numerical solutions and other existing results. The influence of various physical parameters, such as the material attributes (Young modulus, Poisson ratio, etc.), the electrostatic gap, and microsize of the beam on mechanical behavior, or Pull-In voltage of electrostatically actuated microbeams, could also be investigated with these analytical expressions.

\section{Introduction}

Tremendous attention in the field of micro- and nanoelectromechanical systems (MEMS/NEMS) has been observed in the last few decades. Sensors and actuators are being actively developed by applying MEMS/NEMS [1-5], because of their advantage of bias networking simplicity and low power consumption. Radio frequency (RF) switches [6], energy harvesters, inductors [7], and variable capacitors for high radio frequency circuits [8] as well as bio-MEMS $[9,10]$ are typical representatives. The electrostatic force is inversely proportional to the square of the distance between the actuating electrode and the structure. The electrostatic force and large deformations of the structure could usually cause strong nonlinearity. Nathanson [11] first analyzed PullIn instability (i.e., equilibrium instability of electrostatically driven MEMS/NEMS). The Pull-In instability including variables of voltages and deflections and limiting the operational procedure of MEMS/NEMS devices is taken as a basic static instability mechanism. Stable equilibrium exists only when the applied voltage does not exceed a critical Pull-In value, and the structure could safely work and not collapse on the actuating electrode, and vice versa. Therefore, analysis of Pull-In instability and mechanical behavior of MEMS/NEMS devices is key work for their designs and application. Scientists and engineering researchers are mainly interested in research of the static and dynamic stability of MEMS/NEMS under various operating conditions as well as Pull-In parameters' determination.

Investigations on the instability of the single-phase material microbeam are carried out by many researchers [1221]. For conventional MEMS/NEMS sensors or actuators comprised by a single layer material; however, all material properties and operational requirements posed by MEMS structural layers could not simultaneously be met. Therefore, the advantages of functionally graded materials (FGMs) 
could be reflected, such as high fracture toughness, improved stress distribution, the superior stress relaxation, capabilities of withstanding high temperatures, and large thermal gradients. Biomaterials are typically used to form the FGM microbeam [22-30]. FGMs have recently been used as microand nanostructures, such as MEMS and NEMS [31-33], thin films in the form of shape memory alloys [34], and atomic force microscopy (AFM) [35].

Besides residual stress and Pull-In parameters, thermal loading is another basic parameter that can directly affect the system work result. Owing to the electric current, the temperature would be raised, in the operating conditions of the microswitch. As known, thermal actuation could produce large displacements as a result of heat, which is the reason of using FGM as lots of thermal tunable capacitors and microcapacitive thermal sensors [34, 36-43]. Pull-In instabilities in a FGM microplate due to thermal stress caused by the electric current were studied by Hasanyan et al. [36]. The strongly dependent relationship between Pull-In voltage and the temperature and the variation through the two constituents volume fractions thickness could be observed.

FGM microgripper mechanical behavior subjected to thermal load, intermolecular forces, and voltage is studied by Jahangiri et al. [38] through numerical method. Based on modified couple stress theory, a thin FGM microplate buckling behavior under mechanical and thermal force is investigated by the spline finite strip method [39]. Ashoori and Vanini [41] observe thermal stability characteristics of FGM plates under the influences of power law index, the material length scale parameter, and inner and outer radii as well as elastic foundation coefficients. The asymmetric buckling patterns are revealed for special boundary conditions. Via applying von Karman's surface elasticity theory and geometric nonlinearity, Yang and Wang [43] derive an analytical mechanical model for investigating the Pull-In characteristics of CNTs reinforced nanoactuator. Coupled electrostatic loading, thermal stress, dispersion forces as Casimir force and van der Waals, and surface stress are fully considered in the model. From the careful review of this paper, the effectiveness of electrostatically actuated microstructures caused by temperature changes was discussed in a limited number of papers, especially FGM microbeams caused by nonuniform temperature stress.

The purpose of this paper is to propose alternative methods to solve nonlinear response of a cantilever FGM MEMS/NEMS beam actuator, including the effect of fringing field, the length scale, the nonuniform temperature field, van der Waals force, and Casimir force. This paper forms an important extension of the recent research of establishing analytical approximate solutions to a clamped-clamped FGM MEMS/NEMS beam [44]. The present approaches include numerical method as well as analytical approximate method. The brief analytical approximate expressions are constructed via coupling Galerkin formulation with the selection of the shape function. The numerical solutions of this problem are then obtained by establishing an extended system and using shooting method [45]. Compared with numerical shooting solutions, analytical approximate results could give excellent agreements for a wide range of microbeam-center

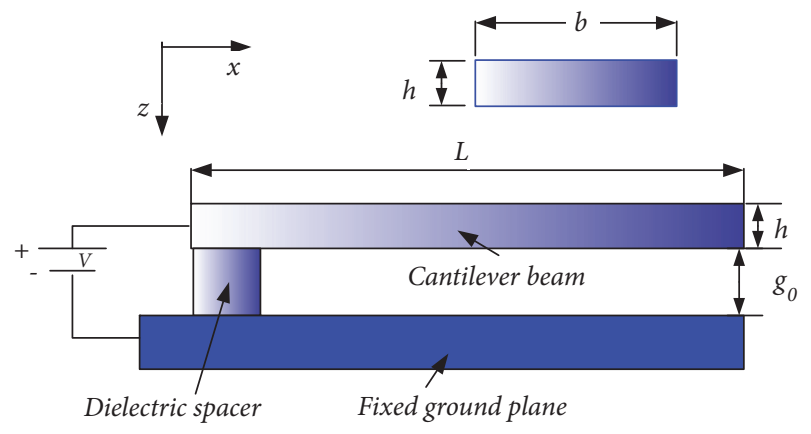

FIGURE 1: Schematic of a FGM microbeam subjected to an electrostatic force.

displacement. Furthermore, these brief analytical solutions can be applied to investigate the dependent relationship between mechanical behavior of electrostatically actuated microbeams and various physical parameters.

\section{Governing Equation}

Figure 1 depicts a FGM microbeam electrostatically actuated by a fixed electrode. A voltage $V$ is used across the microbeam and the electrode fixed below it. Let $x \in[0, L]$ be the horizontal coordinate along the microbeam length and $z$ be the vertical coordinate along the cross section. Furthermore, $(u, w)$ are the axial and vertical translation of a point on the midplane (i.e., $z=0$ ). In this model, the fringing field effect denoted by its first-order correction and the influence of the intermolecular force are taken into account. The nonlinear differential governing equations for the equilibrium of the electromechanical system can be written in the following form $[1,3,31,46]$ :

$$
\begin{aligned}
& A_{1}\left(\frac{d^{2} u}{d x^{2}}+\frac{d w}{d x} \frac{d^{2} w}{d x^{2}}\right)-B_{1} \frac{d^{3} w}{d x^{3}}=0 \\
& B_{1}\left(\frac{d^{3} u}{d x^{3}}+\frac{d w}{d x} \frac{d^{3} w}{d x^{3}}\right)-D_{1} \frac{d^{4} w}{d x^{4}}-\frac{1}{2} C_{1} \frac{d^{4} w}{d x^{4}} \\
& +\left\{A_{1}\left[\frac{d u}{d x}+\frac{1}{2}\left(\frac{d w}{d x}\right)^{2}\right]-N_{T}\right\} \frac{d^{2} w}{d x^{2}} \\
& +\frac{A_{12}}{6 \pi\left(g_{0}-w\right)^{3}}+\frac{\varepsilon_{0} V^{2}}{2\left(g_{0}-w\right)^{2}}\left[1+\frac{2\left(g_{0}-w\right)}{\pi b}\right] \\
& +\frac{\pi^{2} \hbar c}{240\left(g_{0}-w\right)^{4}}=0
\end{aligned}
$$

The cantilever boundary conditions are

$$
\begin{aligned}
& x=0: \\
& u=w=\frac{d w}{d x}=0 ; \\
& x=L:
\end{aligned}
$$




$$
\begin{aligned}
& B_{1}\left[\frac{d u}{d x}+\frac{1}{2}\left(\frac{d w}{d x}\right)^{2}\right]-\left(D_{1}+\frac{1}{2} C_{1}\right) \frac{d^{2} w}{d x^{2}}-M_{T}=0, \\
& B_{1}\left[\frac{d^{2} u}{d x^{2}}+\frac{d w}{d x} \frac{d^{2} w}{d x^{2}}\right]-\left(D_{1}+\frac{1}{2} C_{1}\right) \frac{d^{3} w}{d x^{3}}=0, \\
& A_{1}\left[\frac{d u}{d x}+\frac{1}{2}\left(\frac{d w}{d x}\right)^{2}\right]-B_{1} \frac{d^{2} w}{d x^{2}}-N_{T}=0
\end{aligned}
$$

where

$$
\begin{aligned}
\left(A_{1}, B_{1}, D_{1}\right) & =\int_{-h / 2}^{h / 2} E\left(1, z, z^{2}\right) d z, \\
C_{1} & =\int_{-h / 2}^{h / 2} \frac{E l^{2}}{(1+v)} d z, \\
N_{T} & =\int_{-h / 2}^{h / 2} E \alpha \theta d z, \\
M_{T} & =\int_{-h / 2}^{h / 2} E \alpha \theta z d z
\end{aligned}
$$

Here, $E, \alpha, v, l, b, h, L, g_{0}$ present Young's modulus, coefficient of thermal expansion, the Poisson ratio, a length-scale parameter of material, the width, the thickness $(b>h)$, the length of the beam, and the nominal gap between microbeam and the ground, respectively. Furthermore, $\theta\left(=T(z)-T_{0}\right)$ is the temperature transformation. The parameters $N_{T}$ and $M_{T}$ present thermal force and moment, respectively. The other physical parameters are as follows: the permittivity of free space $\varepsilon_{0}=8.85 \times 10^{-12} \mathrm{~F} \mathrm{~m}^{-1}$, Planck's constant (divided by $2 \pi) \hbar=1.055 \times 10^{-34} \mathrm{~J} \mathrm{~s}$, the Hamaker constant $A_{12}=$ $4 \times 10^{-20} \mathrm{~J}$, the speed of light $c=2.998 \times 10^{8} \mathrm{~m} \mathrm{~s}^{-1}$, and the potential of the fixed electrode $V$. A planar stress statement is considered. For a wide beam $(b \geq 5 h)$, planar strain statement prevails and $E$ must be substituted by $E /\left(1-v^{2}\right)$ and $\alpha$ by $\alpha /(1-v)$.

The material attributes of FGM microbeam are assumed to vary along its thickness [47], and the top surface is comprised with pure metal, the bottom surface from a mixture of ceramic with the metal. The material attributes about $z$ could be written as

$$
\eta(z)=\eta_{m} e^{\beta(z+h / 2)},
$$

where $\eta$ is the material attributes, such as $E, \alpha, v$, and thermal conductivity $K$. The constant $\beta$ is $\beta=(1 / h) \ln \left(\eta_{h} / \eta_{m}\right)$, where $\eta_{m}, \eta_{h}$ are the material attributes at the top and the bottom surface of the microbeam, respectively.

In this paper, thermal effects in two conditions are considered: temperature is raised from the operating conditions of the microswitch; thermal stress is used to the microswitch. For saving space, about the details of (1) and (2) derivation, please see $[44,46]$. Note that, compared with Sun et al. [44], the thermal force and moment in boundary condition (3) make procedure of solution more complex.

Next, (1) and (2) will be converted into dimensionless form. Substituting (1) into (2), and using (3), the controlling equations of the system could be rewritten as the following dimensionless forms:

$$
\begin{aligned}
\frac{d^{4} W}{d s^{4}} & -\frac{\bar{V}^{2}}{(1-W)^{2}}\left[1+\alpha_{1}(1-W)\right]-\frac{\alpha_{2}}{(1-W)^{3}} \\
- & \frac{\alpha_{3}}{(1-W)^{4}}=0 .
\end{aligned}
$$

And the boundary conditions are

$$
\begin{aligned}
s & =0: \\
W & =0, \\
\frac{d W}{d s} & =0 ; \\
s & =\pi: \\
\frac{d^{2} W}{d s^{2}} & =\Theta, \\
\frac{d^{3} W}{d s^{3}} & =0
\end{aligned}
$$

where

$$
\begin{aligned}
W & =\frac{w}{g_{0}}, \\
U & =\frac{u}{g_{0}} \\
s & =\frac{\pi}{2 L} x \\
\alpha_{1} & =\frac{2 g_{0}}{\pi b}, \\
\alpha_{2} & =\frac{A_{12} Z}{6 \pi g_{0}^{4}}\left(\frac{2 L}{\pi}\right)^{4}, \\
\alpha_{3} & =\frac{\hbar c Z \pi^{2}}{240 g_{0}^{5}}\left(\frac{2 L}{\pi}\right)^{4}, \\
Z & =\frac{A_{1}}{A_{1} D_{1}+A_{1} C_{1} / 2-B_{1}^{2}}, \\
\bar{V}^{2} & =\frac{\varepsilon_{0} Z V^{2}}{2 g_{0}^{3}}\left(\frac{2 L}{\pi}\right)^{4}, \\
\Theta & =\left(\frac{B_{1} N_{T}-A_{1} M_{T}}{A_{1} g_{0}}\right)^{2}\left(\frac{2 L}{\pi}\right)^{2} .
\end{aligned}
$$

The exact solution for the above mathematical model of electrostatic-actuated beam problem is hard to obtain, since the nonlinear terms in the model, such as nonlinear electrostatic force, van der Waals force, and the Casimir force, are coupled with the structural deflection. Moreover, the thermal force and moment in boundary condition (7) make solution procedure more complex. This paper is focused on establishing analytical approximate expressions. These 
analytical approximate solutions are presented via applying Galerkin formulation and the assumed deflection function of the micro-/nanobeam.

\section{Analytical Approximate Solution}

In this part, Galerkin formulation is used to construct the analytical approximate expressions. An assumed deflection function $W(s)$ which satisfies the conditions in (7) and $\left.W(s)\right|_{s=0}=a$ (i.e., $\left.w(x)\right|_{x=L / 2}=\zeta=a g_{0}$ ) can be expressed as

$$
\begin{aligned}
W(s)= & \frac{27}{896}(32 a+19 \Theta)(1-\cos s) \\
& -\frac{19 \Theta}{64}(1-\cos 2 s) \\
& +\left(\frac{a}{28}+\frac{19 \Theta}{896}\right)(1-\cos 3 s) \\
& -\frac{3 \Theta}{256}(1-\cos 4 s), \quad s \in\left[0, \frac{\pi}{2}\right] .
\end{aligned}
$$

Substituting (9) into (6), multiplying (6) by $(1-W)^{4}$ and $\phi(s)$, and then calculating the integral subjected to $s$, from 0 to $\pi / 2$, yield

$$
G_{1}-G_{2} \bar{V}^{2}-G_{3}-G_{4}=0 .
$$

Applying (10), the approximate voltage expression is obtained:

$$
\bar{V}=\sqrt{\frac{\left(G_{1}-G_{3}-G_{4}\right)}{G_{2}}},
$$

where the expressions for $G_{1}, G_{2}, G_{3}, G_{4}$ are presented in Appendix.

Via using (8) and (11), the real actuating voltage can be expressed as

$$
V=\sqrt{\frac{\left[\pi^{4} g_{0}^{3}\left(G_{1}-G_{3}-G_{4}\right)\right]}{\left(8 \varepsilon_{0} Z L^{4} G_{2}\right)}},
$$

where

$$
a=\frac{\zeta}{g_{0}} .
$$

In the next part, (12) is explained to excellently calculate the actuating voltage for a classical example of MEMS/NEMS. It is noted that if all the three factors of Casimir force, the fringing field effect, and van der Waals force are included, the actuating voltage expression is more complex than the statement neglecting them.

The dimensionless Pull-In parameters can be expressed in terms of $g_{0}$, through equation $d \bar{V} / d a=0$. In the same way, the actuating Pull-In voltages $V^{\mathrm{P}}$ and Pull-In free-end deflections $\zeta^{\mathrm{P}}$ could be expressed in terms of $g_{0}$, by calculating $\zeta$ from equation $d V(\zeta) / d \zeta=0$. However, equation $d \bar{V} / d a=0$ has multiple roots; the real solution relating to the Pull-In instability should be determined.

\section{Results and Discussion}

4.1. Validation of the Present Solution. In this part, the classical example will be given to illustrate accuracy of the proposed analytical approximate expressions via comparing it with numerical solution and other existing results [4852]. The corresponding numerical solutions are calculated by applying the shooting method [45]. To apply the shooting method to solve the model in (6) and (7), differential equations with initial conditions are expressed as

$$
\begin{aligned}
& \frac{d^{4} W}{d s^{4}}-\frac{\bar{V}^{2}}{(1-W)^{2}}\left[1+\alpha_{1}(1-W)\right]-\frac{\alpha_{2}}{(1-W)^{3}} \\
& -\frac{\alpha_{3}}{(1-W)^{4}}=0, \\
& W(0)=\frac{d W}{d s}(0)=0, \\
& \frac{d^{2} W}{d s^{2}}(0)=\xi, \\
& \frac{d^{3} W}{d s^{3}}(0)=\omega,
\end{aligned}
$$

and the shooting conditions are

$$
\begin{aligned}
W\left(\frac{\pi}{2}\right) & =a, \\
\frac{d^{2} W}{d s^{2}}\left(\frac{\pi}{2}\right) & =\Theta, \\
\frac{d^{3} W}{d s^{3}}\left(\frac{\pi}{2}\right) & =0 .
\end{aligned}
$$

Using the shooting method, the depending relation of the normalized applied voltage $\bar{V}$ and the coefficient " $a$ " will be obtained. Furthermore, adding $\partial \bar{V} / \partial a=0$ into the shooting condition (16), the Pull-In voltage would be presented. For saving space, the detail procedure of the shooting method would not be presented here, while the readers are kindly referred to Yu et al. [45]. It is noted that the above numerical method can be conveniently carried out for solving nonlinear ordinary integral-differential equations describing electrostatically actuated microstructures [45].

Consider a cantilever microbeam without effect of temperature stress. The Pull-In voltage results of the cantilever microbeam are compared with the existing results in this case [53]. The microbeam consisted of single material in this validation example, with the relevant material and geometric parameters listed in Table 1. Comparisons of the Pull-In voltages: the numerical result $V_{\mathrm{N}}^{\mathrm{P}}$ obtained with the shooting method [45], the analytical approximate voltage $V_{\mathrm{Y}}^{\mathrm{P}}$, and other results are listed in Table 2. The relative errors of Pull-In voltage between the present analytical results and [48] are $1.626 \%$ and $1.322 \%$, for narrow and wide beams, respectively. The results from Table 2 reveal good agreements. Moreover, Figure 2 shows that Pull-In voltages of the present analytical approximate results $V_{\mathrm{Y}}^{\mathrm{P}}$ could give excellent agreements with the numerical ones $V_{\mathrm{N}}^{\mathrm{P}}$ obtained by shooting 
TABLE 1: Geometrical and material parameters of the MEMS beam (polysilicon).

\begin{tabular}{lcc}
\hline Variables & Narrow beam & Wide beam \\
\hline Young's modulus, $E(\mathrm{GPa})$ & 77 & 77 \\
Poisson ratio, $v$ & 0.33 & 0.33 \\
Beam length, $L(\mu \mathrm{m})$ & 300 & 300 \\
Beam width, $b(\mu \mathrm{m})$ & 0.5 & 50 \\
the nominal gap, $g_{0}(\mu \mathrm{m})$ & 2.5 & 2.5 \\
Beam thickness, $h(\mathrm{~nm})$ & 1 & 1 \\
\hline
\end{tabular}

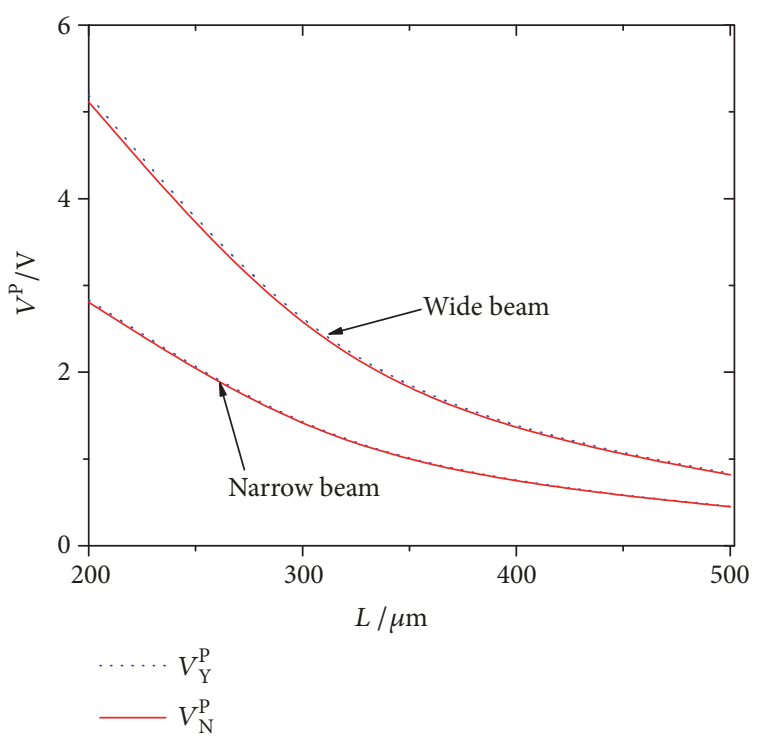

Figure 2: Comparison of the present analytical approximate and numerical Pull-In voltages.

method, respected to the length of the beam. In particular, the maximum relative errors of Pull-In voltage between the present analytical and numerical results with respect to the length of the beam are $0.954 \%$ and $1.546 \%$, for narrow and wide beams, respectively.

4.2. Pull-In Voltage of FGM Microbeam. In this part, the dependent relationship between the Pull-In voltage and uniform/nonuniform temperature field stresses, the microbeam's material attributes, Casimir and van der Waals forces, and length-scale parameter of material are proposed.

Consider a FGM microbeam with the material and geometric parameters given in Table 3. It consisted of two materials: silicon nitride $\left(\mathrm{Si}_{3} \mathrm{~N}_{4}\right)$ and nickel (Ni). The FGM microbeam is diffused from five different silicon nitrides to nickel. According to the various percentage of diffused $\mathrm{Si}_{3} \mathrm{~N}_{4}$ in FGM microbeam, Cases 1-5 are determined and relative to $0-100 \%$, in increments of $25 \%$. The characteristics of Cases 1-5 are given in Table 4. The coefficient of thermal expansion in the thickness direction and variation in Young's modulus are calculated by (5).

Next, some good features of the FGM microbeam over single-phase microbeam with respect to both thermal and electrostatic stress will be illustrated. The microbeam

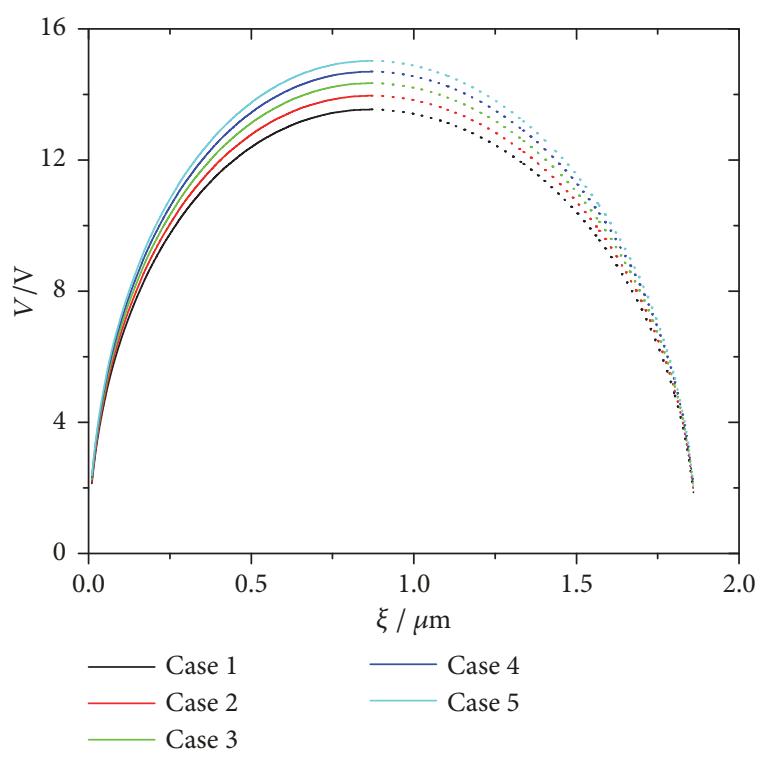

FIGURE 3: Variation of the applied voltage with the free-end deflection of the FGM microbeam.

subjected to $(z)=T_{b}=T_{t}=T_{0}+\Delta T \mathrm{~K}$, where the initial temperature is $T_{0}=300 \mathrm{~K}$ with $\Delta T$ being the temperature change, will initially be considered. The nonuniform temperature field is with the following boundary conditions: $T_{b}=$ $T_{0}-\Delta T K$ at the bottom, and $T_{t}=T_{0}+\Delta T K$ at the top of the microbeam.

Firstly, consider the statement without thermal effects. For the cantilever boundary condition, the dependent relationship between the actuating voltage and the free-end deflection of the FGM microbeam is shown in Figure 3. It can be observed that the stable and unstable solutions are shown by thick solid lines and dot lines in Figure 3, respectively. The increased stiffness of the microbeam (which is due to the inclusion of $\mathrm{Si}_{3} \mathrm{~N}_{4}$ ) gives rise to the increase in Pull-In voltage.

The influence of a uniform temperature field stress on the actuating voltage for a certain free-end deflection of the microbeam for Case 2 is presented in Figure 4. From Figure 4, it is concluded that a decrease in the FGM (Case 2) microbeam Pull-In voltage will be caused by uniform thermal loading. Also the stable and unstable solutions are shown by thick solid lines and dot lines in Figure 4, respectively.

In the following section, the case of a thermally actuated microbeam $(V=6 \mathrm{~V})$ will be investigated. Figure 5 shows the dependent relationship between FGM microbeam free-end deflection and the temperature field change $(V=6 \mathrm{~V})$ under (a) uniform temperature field $T(z)=T_{b}=T_{t}=T_{0}+\Delta T K$ and (b) nonuniform temperature field $\left(T_{b}=T_{0}-\Delta T \mathrm{~K}\right.$ and $\left.T_{t}=T_{0}+\Delta T K\right)$. In Figure 5(a), the free-end deflection of the microbeam severely increases, when $\Delta T$ is large. However, the values of the free-end deflection vary linearly with $\Delta T$ increase, when $\Delta T$ is small. Moreover, from Figure 5(a), one could find that in the case of uniform temperature field (the temperature field boundary condition: $T_{b}=T_{0}-\Delta T \mathrm{~K}$ and $\left.T_{t}=T_{0}+\Delta T K\right)$ the pure nickel microbeam deflection is 
TABLE 2: Pull-In voltage comparison for wide and narrow cantilevers of Table 1.

\begin{tabular}{lllllccc}
\hline \multirow{2}{*}{ Case } & \multicolumn{7}{c}{ Pull-In voltage $(V)$} \\
& {$[47]$} & {$[48]$} & {$[49]$} & {$[50]$} & {$[51]$} & The present Numeric $V_{\mathrm{N}}^{\mathrm{P}}$ & The present Analytical $V_{\mathrm{Y}}^{\mathrm{P}}$ \\
\hline Narrow beam & 1.29 & 1.23 & 1.20 & 1.21 & 1.21 & 1.24 & 1.25 \\
Wide beam & 2.37 & 2.27 & 2.25 & 2.27 & 2.16 & 2.27 & 2.30 \\
\hline
\end{tabular}

Note that intermolecular force is neglected.

TABLE 3: Geometrical and material parameters of the FGM microbeam.

\begin{tabular}{|c|c|c|}
\hline Variables & & Values \\
\hline \multirow{4}{*}{ Nickel } & Young's modulus, $E(\mathrm{GPa})$ & 204 \\
\hline & Poisson ratio, $v$ & 0.3 \\
\hline & coefficient of thermal expansion, $\alpha\left(10^{-6} \mathrm{~K}^{-1}\right)$ & 13.2 \\
\hline & thermal conductivity, $K\left(\mathrm{Wm}^{-1} \mathrm{~K}^{-1}\right)$ & 237 \\
\hline \multirow{4}{*}{ silicon nitride } & Young's modulus, $E(\mathrm{GPa})$ & 310 \\
\hline & Poisson ratio, $v$ & 0.27 \\
\hline & coefficient of thermal expansion, $\alpha\left(10^{-6} \mathrm{~K}^{-1}\right)$ & 3.4 \\
\hline & thermal conductivity, $K\left(\mathrm{Wm}^{-1} \mathrm{~K}^{-1}\right)$ & 30 \\
\hline \multicolumn{2}{|c|}{ Beam width, $b(\mu \mathrm{m})$} & 90 \\
\hline \multicolumn{2}{|c|}{ Beam length, $L(\mu \mathrm{m})$} & 500 \\
\hline \multicolumn{2}{|c|}{ the nominal gap, $g_{0}(\mu \mathrm{m})$} & 2 \\
\hline \multicolumn{2}{|c|}{ Beam thickness, $h(\mu \mathrm{m})$} & 6 \\
\hline \multicolumn{2}{|c|}{ Permittivity of free space, $\varepsilon_{0}\left(\mathrm{~F} \mathrm{~m}^{-1}\right)$} & $8.85 \times 10^{-12}$ \\
\hline \multicolumn{2}{|c|}{ Planck's constant divided by $2 \pi, \hbar(\mathrm{J}$ s) } & $1.055 \times 10^{-34}$ \\
\hline \multicolumn{2}{|c|}{ the Hamaker constant $A_{12}$} & $4 \times 10^{-20} \mathrm{~J}$ \\
\hline \multicolumn{2}{|c|}{ Speed of light, $c\left(\mathrm{~m} \mathrm{~s}^{-1}\right)$} & $2.998 \times 10^{8}$ \\
\hline
\end{tabular}

TABle 4: Properties of 5 cases of FGM microbeams.

\begin{tabular}{|c|c|c|c|c|c|}
\hline Type & $\begin{array}{l}\text { Ceramic percent of } \\
\text { bottom surface (\%) }\end{array}$ & $E_{h}(\mathrm{GPa})$ & $\alpha_{h}\left(10^{-6} \mathrm{~K}^{-1}\right)$ & $\begin{array}{c}\text { Status of bottom } \\
\text { surface }\end{array}$ & Status of top surface \\
\hline 1 & 0 & 204 & 13.2 & \multirow{4}{*}{$\begin{array}{c}\text { Metal rich } \\
\text { "Mixture of metal and } \\
\text { ceramic" }\end{array}$} & \multirow{5}{*}{$\begin{array}{l}\text { Metal rich for all } \\
\text { types }\end{array}$} \\
\hline 2 & 25 & 230.5 & 10.75 & & \\
\hline 3 & 50 & 257 & 8.3 & & \\
\hline 4 & 75 & 283.5 & 5.85 & & \\
\hline 5 & 100 & 310 & 3.4 & Ceramic rich & \\
\hline
\end{tabular}

not affected by the temperature change. In short, nonuniform thermal stress is less effective than uniform temperature loading for microbeam. The dependent relationship between the Pull-In parameters of the FGM microbeam and other different nonuniform temperature distributions, such as $T_{b}=$ $T_{0}+3 \Delta T K$ and $T_{b}=T_{0}-3 \Delta T K$, can also be studied with the present analytical approximate expressions.

In the end, the dependent relationship between PullIn parameters (voltage and deflection) and the microbeam length scale parameter will be investigated in Figure 6. The length scale parameter plays a significant role in the Pull-In parameters. If the length scale parameter is included into the model, the Pull-In voltage and deflection are larger than the case of neglecting it. In addition, with the increase of material length parameters, the results based on modified coupled stress theory are significantly different from those based on classical theory.

\section{Conclusions and Future Work}

In this paper, numerical and analytical approximate expressions to the nonlinear response of a cantilever actuator modeled as a FGM microbeam have been developed. The thermal force and moment in boundary condition make procedure of solution more complex. Based on combination of Galerkin formulation and an assumed deflection shape function, the analytical approximate solution expression to the static behavior of a cantilever FGM microbeam has been constructed. Good agreements of approximate results have been demonstrated for wide range of freeend deflection of cantilever FGM microbeam through comparing them with numerical solutions and other existing results. The effect of thermal stress to the critical parameters of the FGM microbeam, static deformation and the applied voltage, is explicitly analyzed via the analytical 


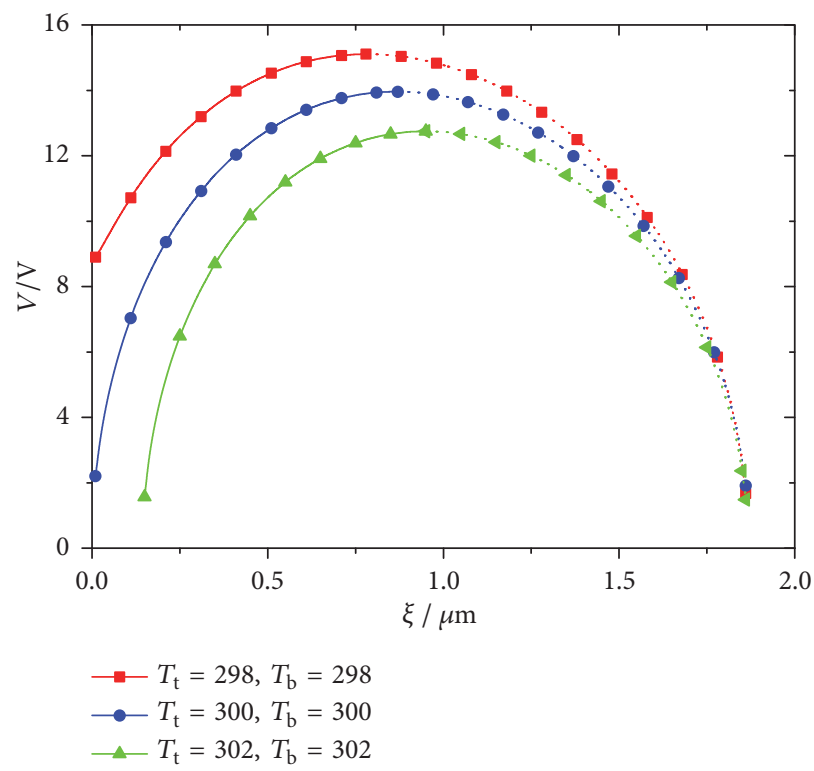

FIGURE 4: Effect of uniform temperature variation on Pull-In voltage of Case 2 FGM microbeam.

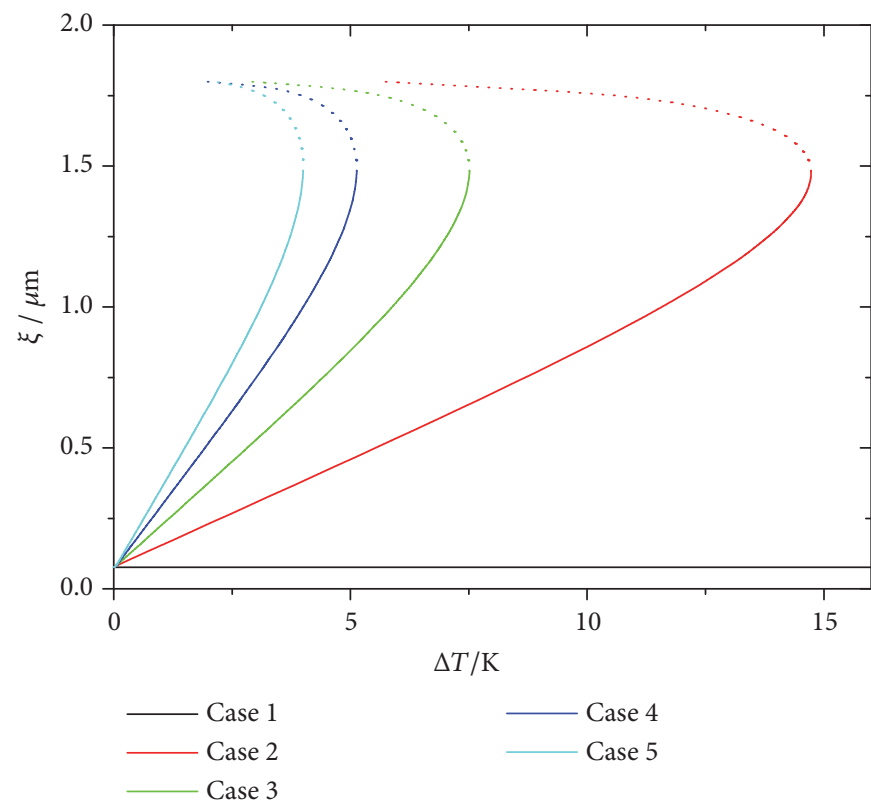

(a)

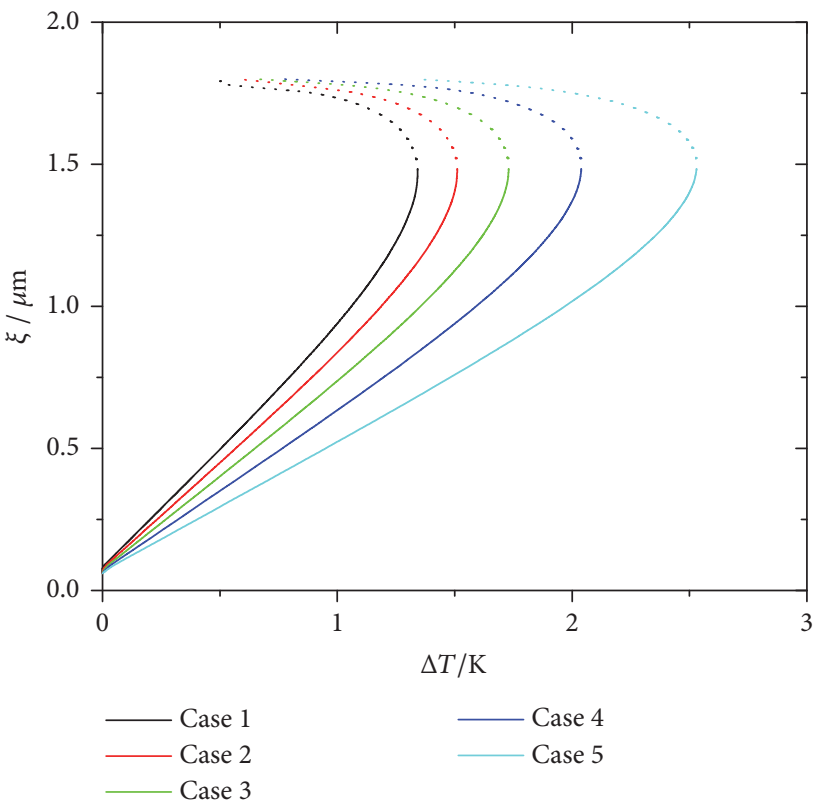

(b)

FIGURE 5: Free-end deflection of FGM microbeam versus temperature change $(V=6 \mathrm{~V})$ under $(\mathrm{a})$ uniform temperature field $T(z)=T_{b}=$ $T_{t}=T_{0}+\Delta T \mathrm{~K}$ and (b) nonuniform temperature field $\left(T_{b}=T_{0}-\Delta T \mathrm{~K}\right.$ and $\left.T_{t}=T_{0}+\Delta T \mathrm{~K}\right)$.

solution. Theoretical results are very useful and convenient for implementation in MEMS/NEMS designs and tests, because the approximate solution expressions are explicit and brief functions of free-end deflection and other geometric and material parameters. In future, advanced approximate solution method, such as [54, 55], will be applied and improved for solving nonlinear vibration of MEMS and some experiments in lab will be done to validate the theoretical results.

\section{Appendix}

$$
\begin{aligned}
G_{1} & =+0.170701 \Theta^{2}+0.0899941 \Theta^{3}+0.0168285 \Theta^{4} \\
& +0.00139811 \Theta^{5}+0.0000438511 \Theta^{6} \\
& +a\left(-1.14253 \Theta-0.911696 \Theta^{2}-0.233155 \Theta^{3}\right. \\
& \left.-0.0247014 \Theta^{4}-0.000943763 \Theta^{5}\right)
\end{aligned}
$$




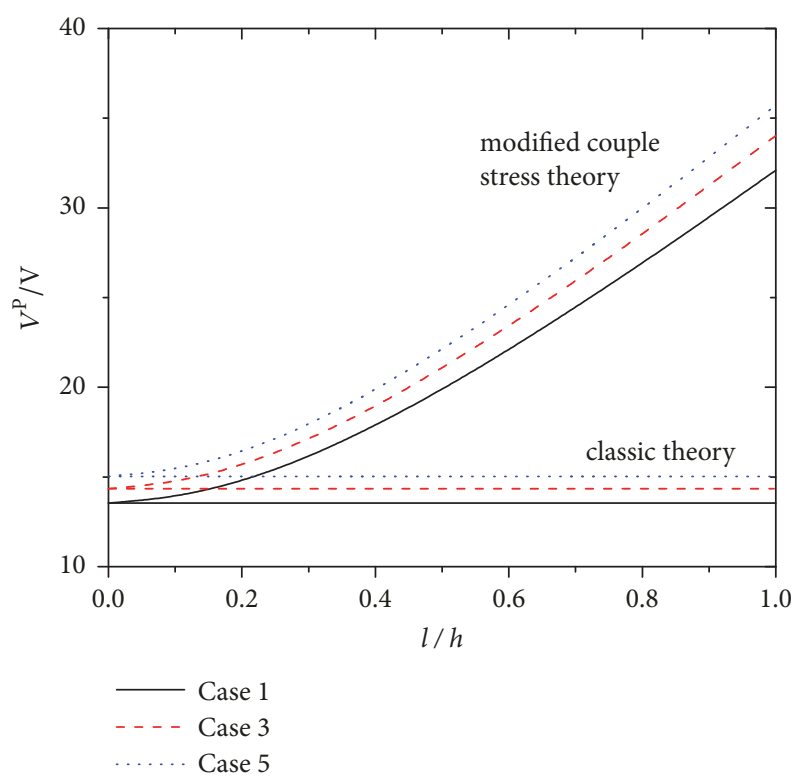

FIGURE 6: Effect of material length parameter on the Pull-In voltage of FGM microbeam.

$$
\begin{aligned}
& +a^{2}\left(0.811445+3.51412 \Theta+1.33044 \Theta^{2}\right. \\
& \left.+0.188159 \Theta^{3}+0.00901511 \Theta^{4}\right)+a^{3}(-2.22134 \\
& \left.-4.05606 \Theta-0.807282 \Theta^{2}-0.0502326 \Theta^{3}\right) \\
& +a^{4}\left(2.30271+2.15722 \Theta+0.1809 \Theta^{2}\right) \\
& -a^{5}(1.10982+0.444256 \Theta)+0.208777 a^{6} \\
G_{2} & =-0.117554\left(1+\alpha_{1}\right) \Theta-(0.0243640 \\
& \left.+0.0365460 \alpha_{1}\right) \Theta^{2}-(0.00138219 \\
& \left.+0.00414656 \alpha_{1}\right) \Theta^{3}-0.000163812 \alpha_{1} \Theta^{4} \\
& +a\left[0.618415\left(1+\alpha_{1}\right)\right. \\
& +\left(0.224530+0.336795 \alpha_{1}\right) \Theta \\
& +\left(0.0181902+0.0545706 \alpha_{1}\right) \Theta^{2} \\
& \left.+0.00280144 \alpha_{1} \Theta^{3}\right]-a^{2}\left[0.794673+1.19201 \alpha_{1}\right. \\
& \left.+0.100056\left(1+3 \alpha_{1}\right) \Theta+0.0209128 \alpha_{1} \Theta^{2}\right] \\
& +a^{3}\left(0.294629+0.883888 \alpha_{1}+0.0888703 \alpha_{1} \Theta\right) \\
& =-(0.117554+0.0121820 \Theta) \Theta+a(0.618415 \\
& =\alpha_{3}[(1533 \pi-6080) \Theta+(-10240+5376 \pi) a] \\
& +0.39736 a^{2} \\
&
\end{aligned}
$$

\section{Data Availability}

The data used to support the findings of this study are available from the corresponding author upon request.

\section{Conflicts of Interest}

The authors declare no conflicts of interest.

\section{Acknowledgments}

The authors gratefully acknowledge the financial support from the Science and Technology Developing Plan Project of Jilin Province (Grant no. 20160520021JH), Science and Technology Project of the 13th Five-Year Plan of Jilin Provincial Department of Education (Grant no. JJKH20190126KJ), and project from Guangzhou Marine Geological Survey (Grant no. 3S2180254424).

\section{References}

[1] R. K. Gupta, Electrostatic pull-in test structure design for insitu mechanical property measurements of microelectromechanical systems (MEMS) [Dissertation], Massachusetts Institute of Technology, 1998.

[2] J. Zhu, H. Stoyanov, G. Kofod, and Z. Suo, "Large deformation and electromechanical instability of a dielectric elastomer tube actuator," Journal of Applied Physics, vol. 108, no. 7, Article ID 074113, 2010.

[3] K. Eom, H. S. Park, D. S. Yoon, and T. Kwon, "Nanomechanical resonators and their applications in biological/chemical detection: nanomechanics principles," Physics Reports, vol. 503, no. 4-5, pp. 115-163, 2011.

[4] R. Ansari, R. Gholami, and S. Sahmani, "Size-dependent vibration of functionally graded curved microbeams based on the modified strain gradient elasticity theory," Archive of Applied Mechanics, vol. 83, no. 10, pp. 1439-1449, 2013.

[5] M. Ren, J. Huang, H. Cai et al., "Nano-optomechanical actuator and pull-back instability," ACS Nano, vol. 7, no. 2, pp. 1676-1681, 2013.

[6] L. X. Zhang and Y.-P. Zhao, "Electromechanical model of RF MEMS switches," Microsystem Technologies, vol. 9, no. 6-7, pp. 420-426, 2003.

[7] X. Sun, Y. Zheng, X. Peng, X. Li, and H. Zhang, "Parylenebased 3D high performance folded multilayer inductors for wireless power transmission in implanted applications," Sensors and Actuators A: Physical, vol. 208, pp. 141-151, 2014.

[8] T. Yasue, T. Komatsu, N. Nakamura et al., "Wideband tunable Love wave filter using electrostatically actuated MEMS variable capacitors integrated on lithium niobate," Sensors and Actuators A: Physical, vol. 188, pp. 456-462, 2012.

[9] Y. Miyashita, M. Iwasaka, and T. Kimura, "Microcrystal-like cellulose fibrils as the diamagnetic director for microfluidic systems," Journal of Applied Physics, vol. 115, no. 17, Article ID 17B519, 2014.

[10] Z. Luo, S. Wang, U. Demirci, T. Lu, F. Xu, and B. Bai, "Antibodybased blood bioparticle capture and separation using microfluidics for global health," Microfluidic Technologies for Human Health, pp. 417-450, 2012. 
[11] H. C. Nathanson, W. E. Newell, R. A. Wickstrom, and J. R. Davis Jr., "The resonant gate transistor," IEEE Transactions on Electron Devices, vol. 14, no. 3, pp. 117-133, 1967.

[12] M. I. Younis, E. M. Abdel-Rahman, and A. Nayfeh, "A reducedorder model for electrically actuated microbeam-based MEMS," Journal of Microelectromechanical Systems, vol. 12, no. 5, pp. 672-680, 2003.

[13] D. Elata and S. Abu-Salih, "Analysis of a novel method for measuring residual stress in micro-systems," Journal of Micromechanics and Microengineering, vol. 15, no. 5, pp. 921-927, 2005.

[14] R. C. Batra, M. Porfiri, and D. Spinello, "Vibrations of narrow microbeams predeformed by an electric field," Journal of Sound and Vibration, vol. 309, no. 3-5, pp. 600-612, 2008.

[15] S. Gutschmidt, "The influence of higher-order mode shapes for reduced-order models of electrostatically actuated microbeams," Journal of Applied Mechanics, vol. 77, no. 4, Article ID 041007, 2010.

[16] S. Krylov and N. Dick, "Dynamic stability of electrostatically actuated initially curved shallow micro beams," Continuum Mechanics and Thermodynamics, vol. 22, no. 6-8, pp. 445-468, 2010.

[17] J. A. Dos Santos and J. Reddy, "Free vibration and buckling analysis of beams with a modified couple-stress theory," International Journal of Applied Mechanics, vol. 4, Article ID 1250026, 2012.

[18] B. Wu, Y. Yu, Z. Li, and Z. Xu, "An analytical approximation method for predicting static responses of electrostatically actuated microbeams," International Journal of Non-Linear Mechanics, vol. 54, pp. 99-104, 2013.

[19] M. Mojahedi, M. Ahmadian, and K. Firoozbakhsh, "The influence of the intermolecular surface forces on the static deflection and pull-in instability of the micro/nano cantilever gyroscopes," Composites Part B: Engineering, vol. 56, pp. 336-343, 2014.

[20] Y. Yu and B. Wu, "An approach to predicting static responses of electrostatically actuated microbeam under the effect of fringing field and Casimir force," International Journal of Mechanical Sciences, vol. 80, pp. 183-192, 2014.

[21] H. M. Sedighi, M. Moory-Shirbani, M. Shishesaz, A. Koochi, and M. Abadyan, "Size-dependent dynamic behavior and instability analysis of nano-scale rotational varactor in the presence of casimir attraction," International Journal of Applied Mechanics, vol. 8, Article ID 1650018, 2016.

[22] Z. Xu and M. J. Buehler, "Strain controlled thermomutability of single-walled carbon nanotubes," Nanotechnology, vol. 20, no. 18, Article ID 185701, 2009.

[23] M. Şimşek, "Vibration analysis of a functionally graded beam under a moving mass by using different beam theories," Composite Structures, vol. 92, no. 4, pp. 904-917, 2010.

[24] L. Ke and Y. Wang, "Size effect on dynamic stability of functionally graded microbeams based on a modified couple stress theory," Composite Structures, vol. 93, no. 2, pp. 342-350, 2011.

[25] S. Chang, A. K. Nair, and M. J. Buehler, "Geometry and temperature effects of the interfacial thermal conductance in copper- and nickel-graphene nanocomposites," Journal of Physics: Condensed Matter, vol. 24, no. 24, Article ID 245301, 2012.

[26] M. Noroozi and L. Jiang, "Buckling and wrinkling of a functionally graded material (FGM) thin film," International Journal of Applied Mechanics, vol. 4, Article ID 1250012, 2012.
[27] Z. Ding, Z. Liu, J. Hu, S. Swaddiwudhipong, and Z. Yang, "Inhomogeneous large deformation study of temperature-sensitive hydrogel," International Journal of Solids and Structures, vol. 50, no. 16-17, pp. 2610-2619, 2013.

[28] M. Zamanzadeh, G. Rezazadeh, I. Jafarsadeghi-Pournaki, and R. Shabani, "Thermally induced vibration of a functionally graded micro-beam subjected to a moving laser beam," International Journal of Applied Mechanics, vol. 6, Article ID 1450066, 2014.

[29] Y. He, S. Guo, Z. Liu, and K. Liew, "Pattern transformation of thermo-responsive shape memory polymer periodic cellular structures," International Journal of Solids and Structures, vol. 71, pp. 194-205, 2015.

[30] Z. Ding, W. Toh, J. Hu, Z. Liu, and T. Y. Ng, "A simplified coupled thermo-mechanical model for the transient analysis of temperature-sensitive hydrogels," Mechanics of Materials, vol. 97, pp. 212-227, 2016.

[31] X. L. Jia, J. Yang, and S. Kitipornchai, "Pull-in instability of geometrically nonlinear micro-switches under electrostatic and Casimir forces," Acta Mechanica, vol. 218, no. 1-2, pp. 161-174, 2011.

[32] H. M. Sedighi, F. Daneshmand, and M. Abadyan, "Dynamic instability analysis of electrostatic functionally graded doublyclamped nano-actuators," Composite Structures, vol. 124, pp. 5564, 2015.

[33] Ş. D. Akbaş, "Free vibration of edge cracked functionally graded microscale beams based on the modified couple stress theory," International Journal of Structural Stability and Dynamics, vol. 17, no. 03, Article ID 1750033, 2017.

[34] Y. Fu, H. Du, and S. Zhang, "Functionally graded TiN/TiNi shape memory alloy films," Materials Letters, vol. 57, no. 20, pp. 2995-2999, 2003.

[35] X. Zhang and J. Jia, "Frictional behavior of micro/nanotextured surfaces investigated by atomic force microscope: a review," Surface Review and Letters, vol. 22, no. 06, Article ID 1530001, 2015.

[36] D. J. Hasanyan, R. C. Batra, and S. Harutyunyan, "Pull-In instabilities in functionally graded microthermoelectromechanical systems," Journal of Thermal Stresses, vol. 31, no. 10, pp. 10061021, 2008.

[37] F. Ebrahimi and E. Salari, "Thermal buckling and free vibration analysis of size dependent Timoshenko FG nanobeams in thermal environments," Composite Structures, vol. 128, pp. 363380, 2015.

[38] R. Jahangiri, H. Jahangiri, and H. Khezerloo, "FGM microgripper under electrostatic and intermolecular van-der waals forces using modified couple stress theory," Steel and Composite Structures, vol. 18, no. 6, pp. 1541-1555, 2015.

[39] M. Mirsalehi, M. Azhari, and H. Amoushahi, "Stability of thin FGM microplate subjected to mechanical and thermal loading based on the modified couple stress theory and spline finite strip method," Aerospace Science and Technology, vol. 47, pp. 356-366, 2015.

[40] S. Sahmani, M. Aghdam, and M. Bahrami, "On the free vibration characteristics of postbuckled third-order shear deformable FGM nanobeams including surface effects," Composite Structures, vol. 121, pp. 377-385, 2015.

[41] A. Ashoori and S. Sadough Vanini, "Thermal buckling of annular microstructure-dependent functionally graded material plates resting on an elastic medium," Composites Part B: Engineering, vol. 87, pp. 245-255, 2016. 
[42] A. R. Ashoori and S. A. Sadough Vanini, "Nonlinear thermal stability and snap-through behavior of circular microstructuredependent FGM plates," European Journal of Mechanics A/Solids, vol. 59, pp. 323-332, 2016.

[43] W. Yang and X. Wang, "Nonlinear pull-in instability of carbon nanotubes reinforced nano-actuator with thermally corrected Casimir force and surface effect," International Journal of Mechanical Sciences, vol. 107, pp. 34-42, 2016.

[44] Y. Sun, Y. Yu, Y. Zhao, N. Zhang, and Y. Ma, "Nonlinear approximate analysis of electrically actuated functionally graded material micro-beam with influence of thermal stress and the intermolecular force," Journal of Computational and Theoretical Nanoscience, vol. 13, no. 1, pp. 492-499, 2016.

[45] Y. Yu, B. Wu, and C. Lim, "Numerical and analytical approximations to large post-buckling deformation of MEMS," International Journal of Mechanical Sciences, vol. 55, no. 1, pp. 95-103, 2012.

[46] Y. Li, S. A. Meguid, Y. Fu, and D. Xu, "Nonlinear analysis of thermally and electrically actuated functionally graded material microbeam," Proceedings of the Royal Society A Mathematical, Physical and Engineering Sciences, vol. 470, no. 2162, Article ID 20130473, 2013.

[47] N. Noda and Z. Jin, "Steady thermal stresses in an infinite nonhomogeneous elastic solid containing a crack," Journal of Thermal Stresses, vol. 16, no. 2, pp. 181-196, 1993.

[48] P. M. Osterberg, Electrostatically Actuated Microelectromechanical Test Structures for Material Property Measurement, Massachusetts Institute of Technology, 1995.

[49] S. Pamidighantam, R. Puers, K. Baert, and H. A. C. Tilmans, "Pull-in voltage analysis of electrostatically actuated beam structures with fixed-fixed and fixed-free end conditions," Journal of Micromechanics and Microengineering, vol. 12, no. 4, pp. 458-464, 2002.

[50] S. Chowdhury, M. Ahmadi, and W. C. Miller, "A closed-form model for the pull-in voltage of electrostatically actuated cantilever beams," Journal of Micromechanics and Microengineering, vol. 15, no. 4, pp. 756-763, 2005.

[51] A. Ramezani, A. Alasty, and J. Akbari, "Closed-form solutions of the pull-in instability in nano-cantilevers under electrostatic and intermolecular surface forces," International Journal of Solids and Structures, vol. 44, no. 14-15, pp. 4925-4941, 2007.

[52] R. Soroush, A. Koochi, A. S. Kazemi, A. Noghrehabadi, H. Haddadpour, and M. Abadyan, "Investigating the effect of Casimir and van der Waals attractions on the electrostatic pullin instability of nano-actuators," Physica Scripta, vol. 82, no. 4, Article ID 045801, 2010.

[53] H. A. C. Tilmans and R. Legtenberg, "Electrostatically driven vacuum-encapsulated polysilicon resonators: Part II. theory and performance," Sensors and Actuators A: Physical, vol. 45, no. 1, pp. 67-84, 1994.

[54] G. Giunta, S. Belouettar, and E. Carrera, "Analysis of FGM beams by means of classical and advanced theories," Mechanics of Advanced Materials and Structures, vol. 17, no. 8, pp. 622-635, 2010.

[55] E. Carrera, G. Giunta, and M. Petrolo, Beam Structures: Classical and Advanced Theories, Wiley-Blackwell, 2011. 


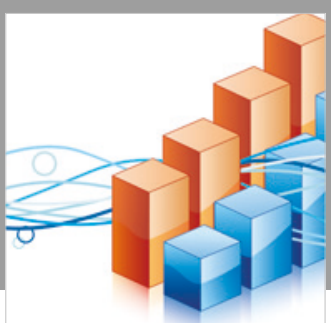

Advances in

Operations Research

\section{-n-m}
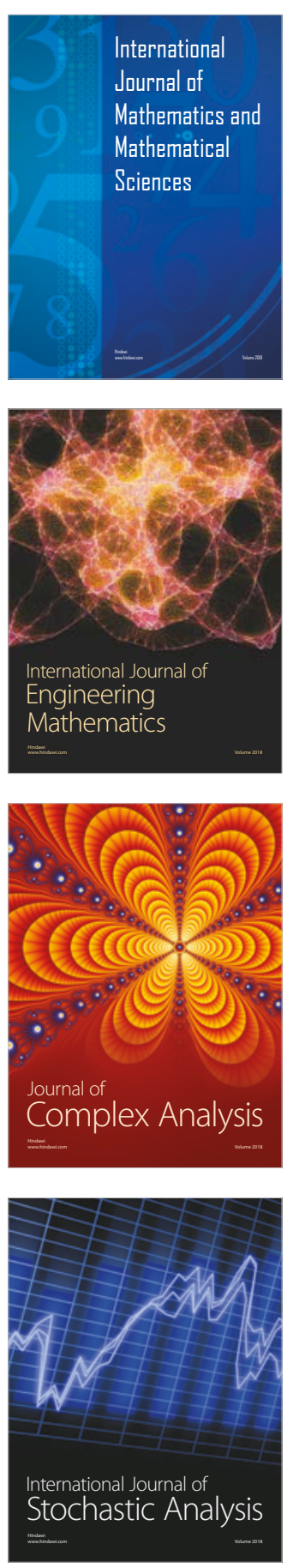
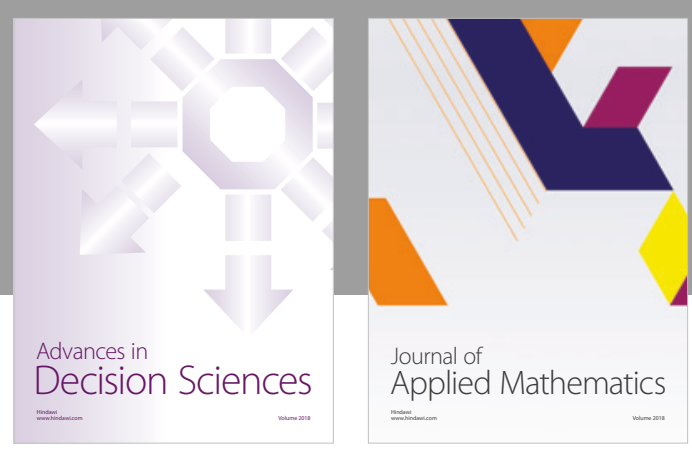

Journal of

Applied Mathematics
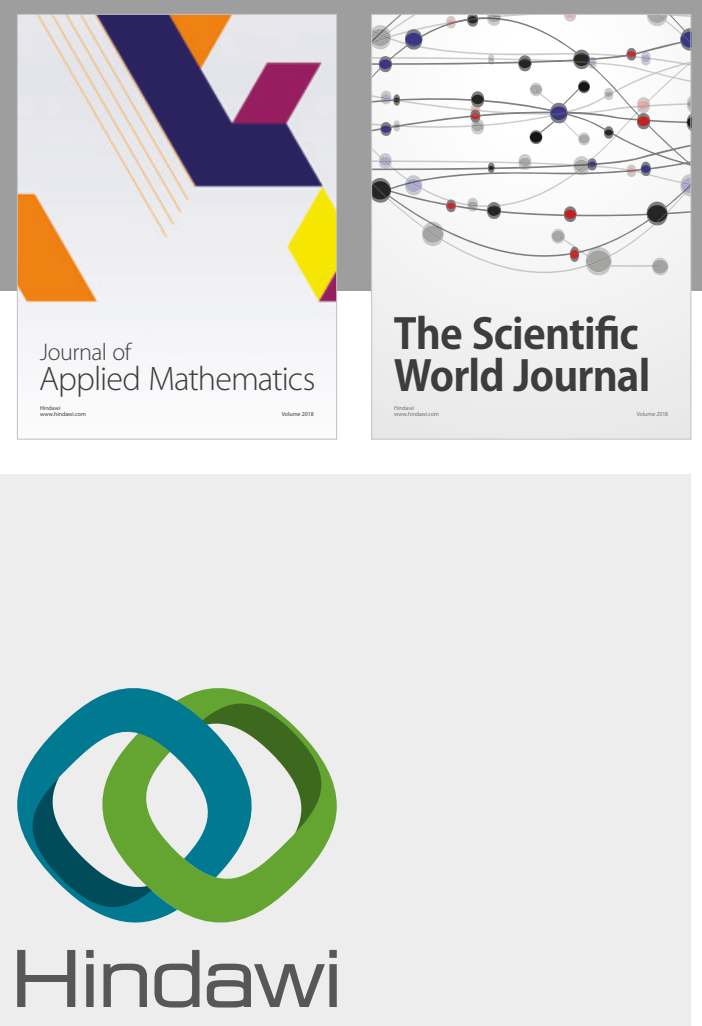

Submit your manuscripts at

www.hindawi.com

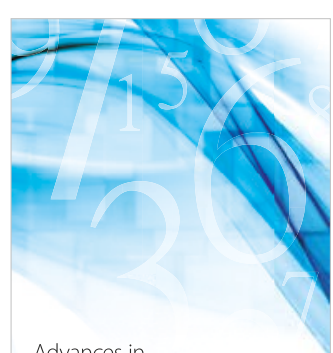

Advances in
Numerical Analysis
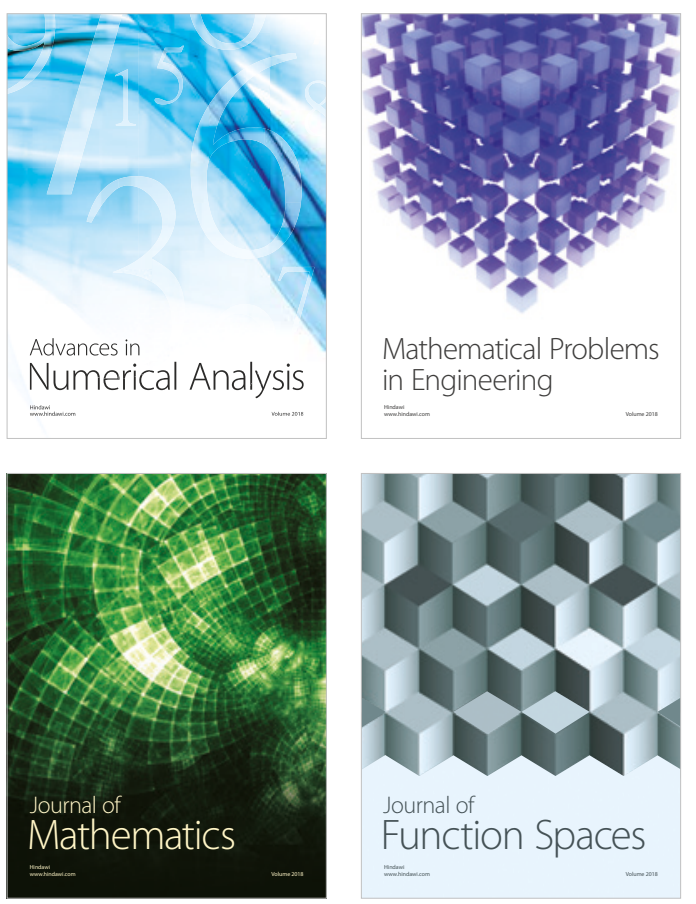

Mathematical Problems in Engineering

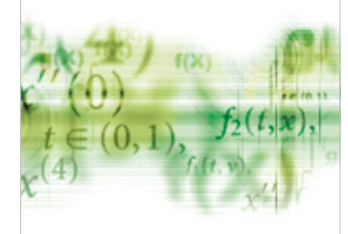

International Journal of

Differential Equations

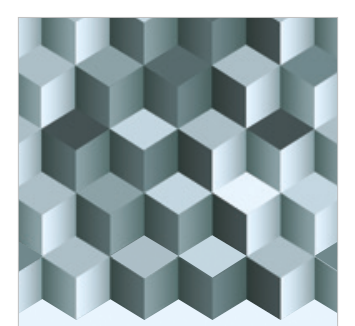

Journal of

Function Spaces

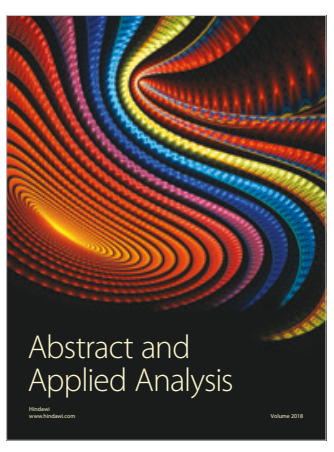

The Scientific

World Journal

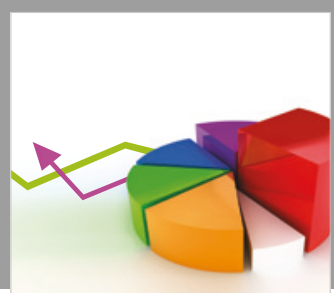

Journal of

Probability and Statistics
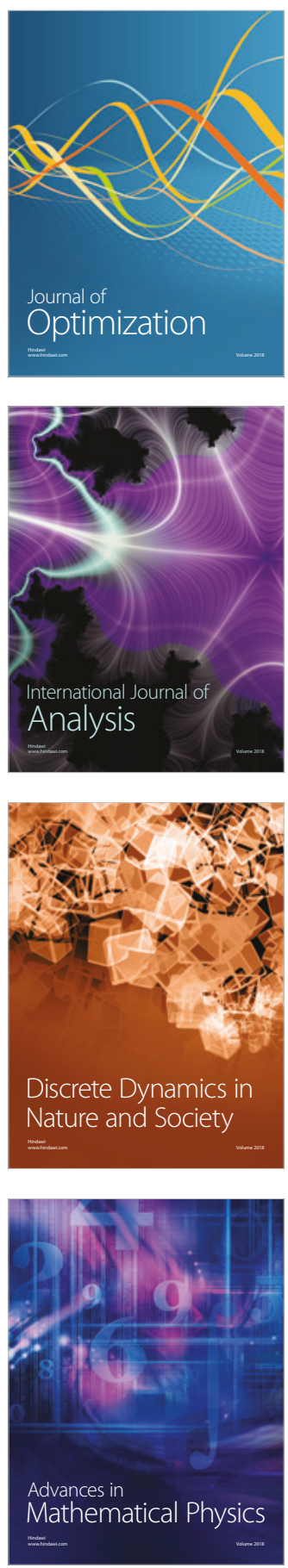